\title{
Effect of activated carbon on bloating properties of artificial lightweight aggregates containing coal reject ash and bottom ash
}

\author{
Min A Kang and Seunggu Kang ${ }^{\dagger}$ \\ Department of Advanced Materials Engineering, Kyonggi University, Suwon 443-760, Korea
}

(Received April 4, 2013)

(Revised August 2, 2013)

(Accepted August 6, 2013)

\begin{abstract}
The coal bottom ash and reject ash discharged from a coal-fired power plant are difficult to recycle so most of them are mainly landfill-disposed. In this study, the artificial aggregate were produced using reject ash, bottom ash and dredged soil emitted from the coal-fired power plant in Korea and the effect of experimental factors on the bloating behavior and the properties of the aggregates were analyzed. In particular, a lot of unburned carbon in the reject ash was removed by calcination and the activated carbon was added to batch powders then the dependence of those process upon bloating properties of artificial aggregate were investigated. For this purpose, the specific gravity and water absorption values of artificial aggregates were investigated in conjunction with microstructural observations. This study could contribute to increase the recycling rate of the reject ash.
\end{abstract}

Key words Artificial aggregate, Bloating, Carbon, Reject ash, Coal bottom ash, Recycling, Calcination

\section{석탄 잔사회 및 바닥재가 포함된 인공경량골재의 발포특성에 미치는 활성탄소의 영향}

강민아, 강승구 ${ }^{\dagger}$

경기대학교 신소재공학과, 수원, 443-760

(2013년 4월 4일 접수)

(2013년 8월 2일 심사완료)

(2013년 8월 6일 게재확정)

요 약 화력발전소에서 배출되는 석탄 바닥재 및 잔사회는 재활용이 힘든 폐자원이어서 주로 매립 처분되고 있다. 본 연구에서는 국내 화력발전소에서 배출된 석탄 잔사회, 바닥재 그리고 준설토를 혼합하여 인공골재를 제조하고, 실험인자가 골재의 발포거동 및 물성에 미치는 영향을 분석하였다. 특히 미연탄소가 많이 포함되어 있는 잔사회에 대하여 하소 처리를 한 뒤, 인위적으로 활성탄소를 첨가함으로서 하소유무 및 활성탄소 첨가량이 인공골재의 발포특성에 미치는 영향을 조사하 였다. 이를 위해 인공골재의 부피비중 및 흡수율 값을 시편의 미세구조 관찰 결과와 연계하여 고찰함으로서, 잔사회의 재 활용율 제고에 일조하고자 하였다.

\section{1. 서 론}

우리나라 총 전기생산량 중 화력 발전이 차지하는 비 율은 약 $37 \%$ 이며, 화력발전 과정에서 배출되는 석탄회 는 연간 835만 톤에 이른다[1]. 석탄회는 발생 위치에 따라 크게 비산재(fly ash)와 바닥재(bottom ash)로 구분

\footnotetext{
Corresponding author

Tel: +82-31-249-9767

Fax: +82-31-249-9774

E-mail: sgkang@kgu.ac.kr
}

되는데, 비산재와 바닥재의 발생 비율은 대략 $8: 2$ (무게 기준) 정도로 알려져 있다[2]. 비산재는 입도가 미세하고 시멘트를 대체할 수 있는 조성을 갖고 있어 대부분 재활 용되고 있다. 그러나 비산재 중 탄소함량이 많고 입도가 큰 것은 잔사회(reject ash)라고 하며 이는 거의 재활용 되지 못하고 있는 실정이다[3]. 다행히 최근 들어 잔사 회를 재활용하여 인공경량골재를 제조하고, 이를 구조 및 비구조용 콘크리트 골재 또는 각종 기능성 다공체로 활용하려는 연구가 활발히 진행되고 있다[4].

통상 비중 1.0 이하의 경량 세라믹 골재를 제조하려면 
원료 내에 적절한 가스 및 액상 발생 성분들이 존재하여 야 한다[4]. 또한 경량골재를 제조할 때 주로 사용되는 소성법은 소위 '직화 소성법(flash sintering)'으로서, 이 는 소성온도로 가열된 로에 성형시편을 넣고 일정 시간 유지한 후 바로 대기 중으로 배출시키는 방식이다. 직화 소성법으로 부터 제조된 골재의 내부는 검은 색을 띠고 있어 블랙코어(black core)라 하고, 이를 둘러싸고 있는 붉은 색의 바깥 부분을 외피(shell)라고 칭한다[3-6].

한편, 탄소 함량이 과도하게 많은 원료를 사용할 경우, 가스가 골재시편 내부가 아닌 외피에서 발포될 수 있으 며 이를 소위 '표면발포'라 한다. 그런데 표면발포가 일 어난 시편은 내부발포 시편에 비해 비중 및 흡수율이 높 다는 단점이 있어 경량골재를 생산할 때 가능한 억제해 야 할 현상으로 인식되고 있다[7].

본 실험에서는 미연탄소가 많이 포함되어 있어 잔사회 를 하소하여 미연탄소를 제거한 뒤, 인위적으로 활성탄 소를 첨가함으로서, 잔사회 하소유무 및 활성탄소량이 인공골재의 발포특성에 미치는 영향을 조사하였다. 이를 위해 인공골재의 부피비중 및 흡수율 값을 미세구조 관 찰 결과와 연계하여 고찰함으로서, 잔사회의 재활용율 재고에 일조하고자 하였다.

\section{2. 실험방법}

본 연구에 사용된 석탄 잔사회(reject ash) 및 바닥재 (bottom ash)는 국내 ' $\mathrm{Y}$ ' 화력발전소에서 발생한 것이고, 준설토(dredged soil) 역시 해당 발전소 건설시 준설된
토양으로 각 원료의 조성을 Table 1에 나타내었다. 잔사 회는 $1000^{\circ} \mathrm{C}$ 에서 3 시간 동안 하소하여 미연탄소를 제거 하여 사용하였다. 이로부터 골재를 제조할 때, 잔사회, 준설토, 바닥재를 각각 $5: 3: 2$ (무게비)로 혼합하고, 활 성탄소를 0 2 wt\% 범위로 첨가하여 골재 내 탄소량을 조절하였다. 본 연구에서 제조된 인공골재의 배치(batch) 조성, 잔사회 하소 유무 그리고 활성탄소 첨가량을 Table 2에 나타내었다. 골재 시편명에서 ' $\mathrm{CAL}$ '은 잔사회를 하 소(calcination)하여 제조되었다는 의미이며, 숫자는 활성 탄소 첨가량 $(\mathrm{wt} \%)$ 을 뜻한다. 'AR' 시편은 잔사회를 하 소하지 않고, 활성탄소도 참가하지 않은, 원료 그대로 (asreceived)를 배합하여 제조된 것이다.

준비된 배치분말을 $24 \mathrm{~h}$ 동안 볼밀(ball mill)기로 혼 합한 뒤, 실험자의 손으로 직경 $10 \mathrm{~mm}$ 의 구형 성형체를 성형하였고, 이를 $110^{\circ} \mathrm{C}$ 에서 $24 \mathrm{~h}$ 동안 건조 후, 직화 소성하여 인공골재를 제조하였다. 이때 소성온도는 1050 $1250^{\circ} \mathrm{C}$ 범위로 하고, 소성시간은 10 분으로 고정하였다.

원료의 화학조성 분석을 위하여 XRF(ZSX-100e, Rigaku, $\mathrm{Japan}$ )를 이용하였고, 소성체 절단면의 미세구조를 관찰 하기 위하여 광학현미경(DCS-105, SOMETECH Vision, Korea)을 사용하였다. 또한 소성체의 온도변화에 따른 비중 및 흡수율 측정은 'KS F 2503'의 실험방법을 적 용하였다.

\section{3. 결과 및 고찰}

본 연구에서 사용된 원료의 화학조성을 표시함에 있어

Table 1

Chemical compositions of raw materials

(wt\%)

\begin{tabular}{|c|c|c|c|c|c|c|c|c|c|c|c|c|c|}
\hline \multirow[b]{2}{*}{ Raw materials } & \multirow{2}{*}{$\begin{array}{l}\text { Frame } \\
\text { oxide }\end{array}$} & \multicolumn{2}{|c|}{ Neutral oxides } & \multicolumn{5}{|c|}{ Fluxing oxides } & \multicolumn{5}{|c|}{ Others } \\
\hline & & $\mathrm{Al}_{2} \mathrm{O}_{3}$ & $\mathrm{Fe}_{2} \mathrm{O}_{3}$ & $\mathrm{CaO}$ & $\mathrm{MgO}$ & $\mathrm{Na}_{2} \mathrm{O}$ & $\mathrm{K}_{2} \mathrm{O}$ & $\mathrm{MnO}$ & $\mathrm{TiO}_{2}$ & $\mathrm{P}_{2} \mathrm{O}_{5}$ & $\mathrm{C}$ & I.L & Total \\
\hline Reject ash & 60.1 & 19.1 & 3.0 & 1.1 & 0.5 & 0.3 & 0.5 & 0 & 1.0 & 0.4 & 9.1 & 4.9 & 100 \\
\hline Bottom ash & 60.9 & 25.5 & 4.1 & 1.0 & 0.9 & 0.1 & 3.2 & 0.0 & 0.8 & 0.8 & 1.7 & 1.0 & 100 \\
\hline Dredged soil & 70.7 & 14.4 & 3.8 & 0.8 & 0.2 & 2.5 & 2.7 & 0.0 & 0.8 & 0.0 & 0.0 & 4.1 & 100 \\
\hline
\end{tabular}

Table 2

Batch composition of artificial aggregates

(wt $\%)$

\begin{tabular}{|c|c|c|c|c|c|}
\hline Specimen I.D. & Reject ash & Dredged soil & Bottom ash & Activated carbon added & Calcination of Reject ash \\
\hline $\begin{array}{l}\text { CAL }^{*}-0 \\
\text { CAL-1 } \\
\text { CAL-2 } \\
\text { A-R }\end{array}$ & 50 & 30 & 20 & $\begin{array}{l}0 \\
1 \\
2 \\
0\end{array}$ & $\begin{array}{l}\bigcirc \\
\bigcirc \\
\bigcirc \\
\times\end{array}$ \\
\hline
\end{tabular}

*CAL means 'calcined'.

**A-R denotes 'As-received'. 
(Table 1), 조성 산화물을 전통적인 세라믹 분류법에 의 거하여 산성, 중성, 그리고 융제(flux) 산화물로 분류하 였다. 산성 산화물은 세라믹스의 골격(flame)을 이루는 비금속 산화물로 $\mathrm{RO}_{2}$ 그룹 $(\mathrm{R}=$ 금속원소 $)$ 에 속하며 $\mathrm{SiO}_{2}$ 가 대표적이다. 중성 산화물은 양쪽성 원소 산화물로서 $\mathrm{R}_{2} \mathrm{O}_{3}$ 그룹에 속하며 $\mathrm{Al}_{2} \mathrm{O}_{3}$ 가 이에 속한다. 그리고 융제 산화물은 액상형성을 촉진하는 1족 또는 2족 금속 산화 물로서 $\mathrm{RO}$ 또는 $\mathrm{R}_{2} \mathrm{O}$ 그룹에 속한다.

잔사회(reject ash)는 바닥재(bottom ash)와 비교하면 $\mathrm{SiO}_{2}$ 함량은 비슷하나 $\mathrm{Al}_{2} \mathrm{O}_{3}$ 양이 적으며, 잔사회에 포 함되어 있는 융제는 $2.4 \mathrm{wt} \%$ 로 바닥재(5.2 wt\%) 경우에 비해 적은 것을 알 수 있다. 한편 준설토(dredged soil) 는 잔사회 및 바닥재보다 $\mathrm{SiO}_{2}$ 양이 많고 $(70.7 \mathrm{wt} \%$ ), $\mathrm{Al}_{2} \mathrm{O}_{3}$ 양은 적으나, 융제양이 $6.2 \mathrm{wt} \%$ 로 매우 높다.

본 실험에서 가장 중요한 인자는 각 원료에 함유된 탄 소의 함량이다. 잔사회의 탄소함량은 $9.1 \mathrm{wt} \%$ 로 매우 높 았으며, 바닥재의 경우 $1.7 \mathrm{wt} \%$ 의 탄소함량을 나타내었 다. 한편, 준설토는 원료 내 탄소를 함유하고 있지 않았 다. 본 실험에선 탄소함량이 매우 높은 잔사회를 하소함 으로써 골재 내 전체 탄소량을 현저히 줄일 수 있었고, 이에 활성탄소를 $0 \sim 2 \mathrm{wt} \%$ 첨가함으로서 골재 내의 탄 소함량을 조절하였다.

잔사회 하소 및 활성탄소 첨가 후, 각 시편에 존재하 는 탄소의 총량을 계산하여 Table 3에 나타내었다. 잔사 회를 하소하고 활성탄소를 넣지 않은 $\mathrm{CAL} 0$ 의 시편에도 미량의 탄소가 존재하는데 $(0.36 \mathrm{wt} \%)$, 이는 원료 성분 중 바닥재에 존재하는 탄소 때문이다. 하소하지 않은 잔 사회를 사용한 $\mathrm{AR}$ 시편의 탄소함량은 $5.26 \mathrm{wt} \%$ 로 가장 높게 나타났다.

본 연구에서 제조한 인공골재의 소성 온도에 따른 비 중값을 Fig. 1에 나타내었다. 대부분의 시편에서 소성온 도의 증가에 따라 비중이 증가하는 치밀화 거동을 보이 다가 특정 온도 이후에서는 비중이 감소하는 발포특성을 나타내었다. $\mathrm{AR}$ 시편을 제외한 모든 시편들은 1050 $1150^{\circ} \mathrm{C}$ 구간에서 소결온도 증가에 따라 밀도가 증가하 여 1150 프에서 최대 밀도값을 나타내었다. 그러나 그 이 상의 온도에서는 밀도가 낮아지며, $1250^{\circ} \mathrm{C}$ 에서 소결된 골재들은 $\mathrm{AR}$ 을 제외하고는 모두 약 0.95 의 낮은 비중값 을 나타내었다. 한편 $\mathrm{AR}$ 시편은 $1050 \sim 1100^{\circ} \mathrm{C}$ 구간에서 온도 증가에 따라 밀도가 증가하였고 그 이상의 소성온 도에서는 점차 밀도가 감소하였다. 그러나 온도에 따른 밀도 감소율이 다른 시편들에 비해 매우 낮았다.

Table 3

Total carbon content in artificial aggregates

(wt\%)

\begin{tabular}{lllll}
\hline Specimen I.D. & CAL-0 & CAL-1 & CAL-2 & A-R \\
\hline Content of carbon & 0.36 & 1.36 & 2.36 & 4.82 \\
\hline
\end{tabular}

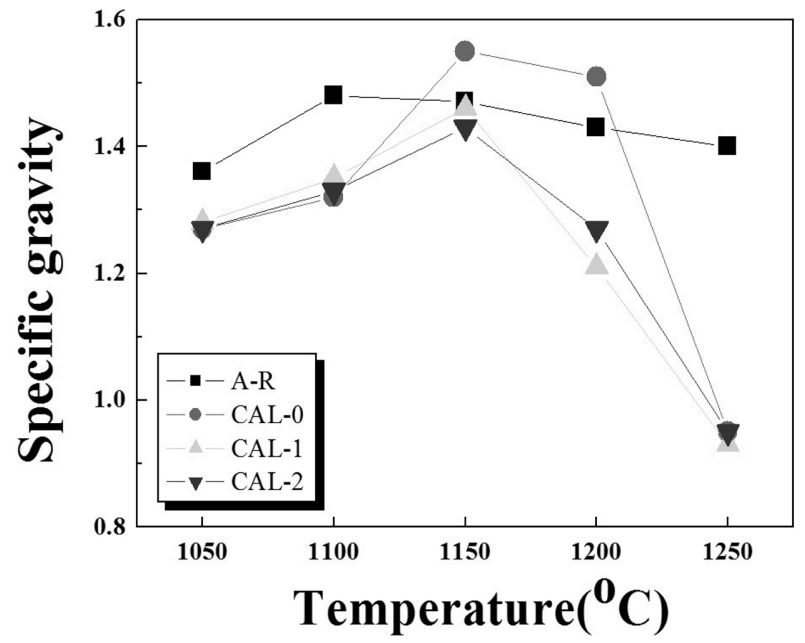

Fig. 1. Specific gravity of artificial aggregates sintered at 1050 $1250^{\circ} \mathrm{C}$ for $10 \mathrm{~min}$ in electric furnace as a function of carbon content.

골재 원료의 탄소함량이 임계값 이상으로 높은 경우, 골재 소결 시 발포현상이 내부에 발생하지 못하고 표면 층에서만 일어나는 소위 '표면발포' 거동을 나타낸다 [7]. $\mathrm{AR}$ 시편에는 원료자체에 존재하는 미연탄소량이 $4.82 \mathrm{wt} \%$ 로 매우 높다. 따라서 내부발포 없이 표면층만 발포되어 소결온도 증가에 따른 밀도값 감소율이 다른 시편들에 비해 낮게 나타난 것으로 생각된다. 원료 중 잔사회를 하소한 시편(CAL0)의 발포온도가 $1150^{\circ} \mathrm{C}$ 이상으로 $\mathrm{AR}$ 시편의 $1100^{\circ} \mathrm{C}$ 보다 높은 것은 미연탄소량이 $0.36 \mathrm{wt} \%$ 로 낮아서 소결 시 치밀화 거동이 향상되었기 때문으로 보인다. 통상 세라믹 소결 시 미연탄소 존재는 치밀화를 방해하는 것으로 알려져 있다.

한편, 하소된 잔사회를 사용한 배치원료에 활성탄소를

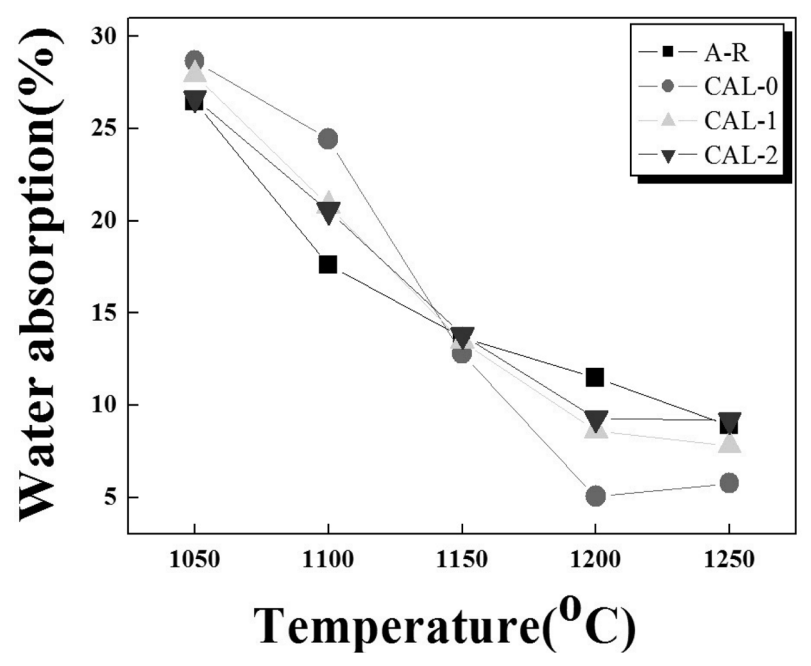

Fig. 2. Water absorption of artificial aggregates sintered at $1050 \sim 1250^{\circ} \mathrm{C}$ for $10 \mathrm{~min}$ in electric furnace as a function of carbon content. 


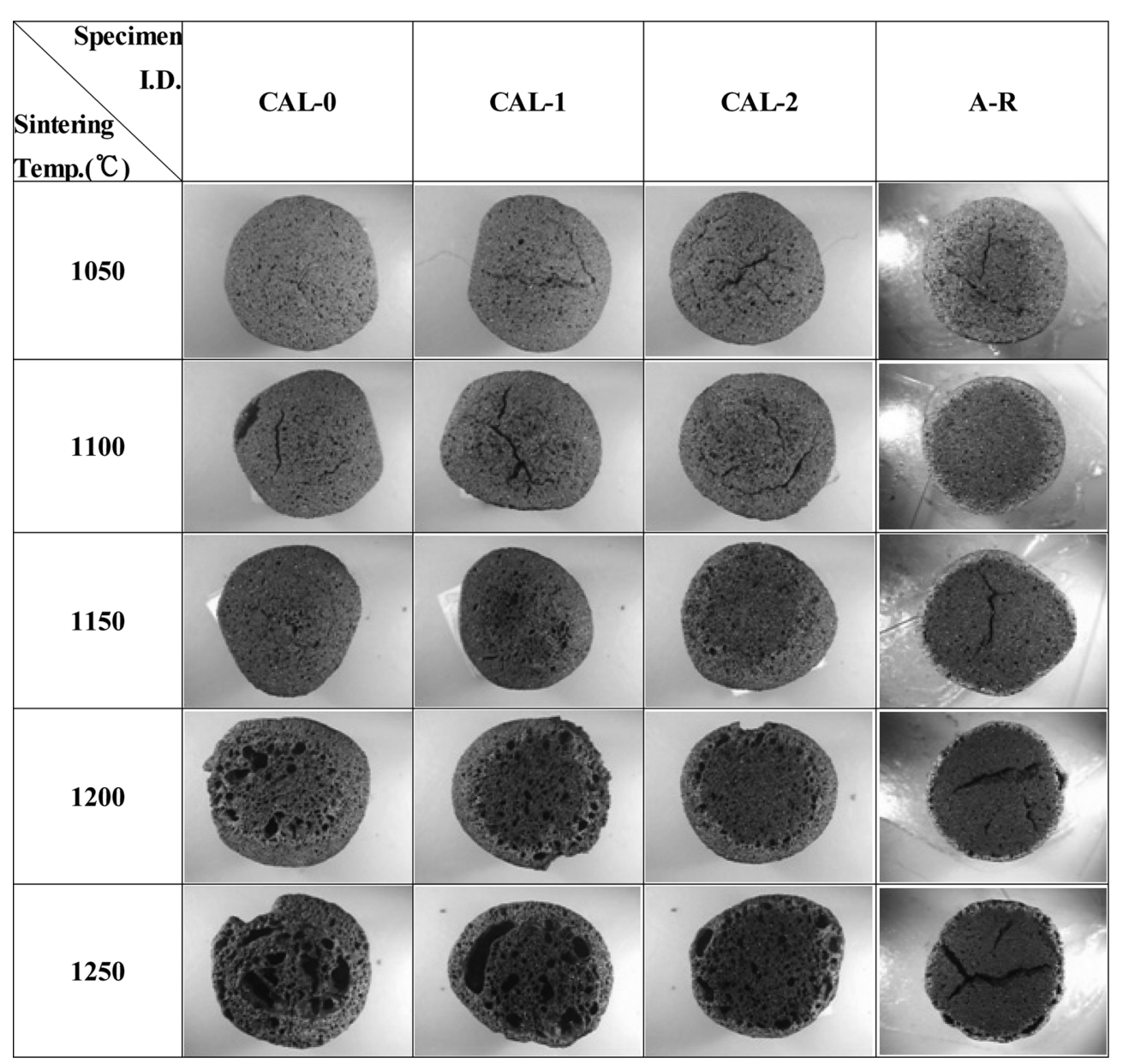

Fig. 3. Optical microscopic photographs for cut cross section of artificial aggregates sintered at $1050 \sim 1250^{\circ} \mathrm{C}$ for $10 \mathrm{~min}$ in electric furnace.

각각 1 및 $2 \mathrm{wt} \%$ 첨가한 CAL1 및 CAL2 시편은 경량 화 온도가 $1150^{\circ} \mathrm{C}$ 로 $\mathrm{CAL} 0$ 시편과 같았으나, 1150 $1200^{\circ} \mathrm{C}$ 소결온도 범위에서 밀도값이 CAL0 시편에 비해 낮게 나타나, 활성탄소 첨가가 발포경향을 향상시켰음을 알 수 있다.

탄소량 및 소결온도 변화에 따른 인공골재의 흡수율을 Fig. 2에 나타내었다. 모든 시편들은 소성온도의 증가에 따라 흡수율이 감소하는 경향을 보였다. 이는 소성온도 와 함께 표면에 형성된 액상의 양도 함께 많아져서, 표 면의 개기공(open pore)이 막히기 때문이다. CAL0 시편 은 다른 시편에 비하여 온도에 따른 흡수율 감소가 급격 하였는데 이는 표면에 다량의 액상이 형성되었기 때문으 로 생각된다. 인위적으로 활성탄소를 첨가하지 않은 시 편 즉, $\mathrm{CAL}-0$ 이 다른 시편에 비해 고온에서 액상이 많 이 생성되는 것으로 보아, 첨가된 활성탄소가 고온에서 시편의 액상 생성을 억제하는 것으로 생각되나, 정량적 인 결론은 추가적인 연구가 필요할 것으로 판단된다. 또 한 골재 내에 활성탄소 함량이 높을수록 흡수율 감소 기 울기가 완만해졌다. 이로 인하여 $1200^{\circ} \mathrm{C}$ 이상에서 소성된
골재의 흡수율은 활성탄소 첨가량에 비례하여 높아졌다.

골재 내 탄소함량 및 소결온도에 따른 골재 내부 단면 사진을 Fig. 3에 나타내었다. 탄소의 양이 가장 적은 시 편인 $\mathrm{CAL} 0$ 는 $1200^{\circ} \mathrm{C}$ 에서 부터 발포되었고 내부에 다 량의 기공이 존재하였다. 그러나 이러한 내부 발포 현상 은 골재 내에 함유된 탄소량이 증가함에 따라 점차 표면 발포 거동으로 변화되었다. 특히 탄소함량이 가장 많은 골재(AR)는 전형적인 표면 발포기구에 의한 단면구조를 보였다. 또한 $\mathrm{AR}$ 시편 내부에 거대한 방사형의 균열이 관찰되었는데 이는 많은 량의 탄소에 기인하는 다량의 가스가 급격히 시편 밖으로 빠져 나가는 과정에서 발생 된 것으로 생각된다. 또한 $1150^{\circ} \mathrm{C}$ 이상의 온도에서 소 결된 시편은 붉은색 표피(shell)와 검은색의 중심부(core) 로 구성되어 있어, 소위 블랙코어(black core) 현상이 발 생했음을 알 수 있다. 또한 골재 중심부에 존재하는 블 랙코어의 크기가 활성 탄소 함량에 비례하여 증가함을 알 수 있다.

블랙코어 현상이 나타난 골재의 단면구조에서, 표피의 붉은색은 산화 분위기에서 소성된 $\mathrm{Fe}_{2} \mathrm{O}_{3}$ 의 영향 때문이 


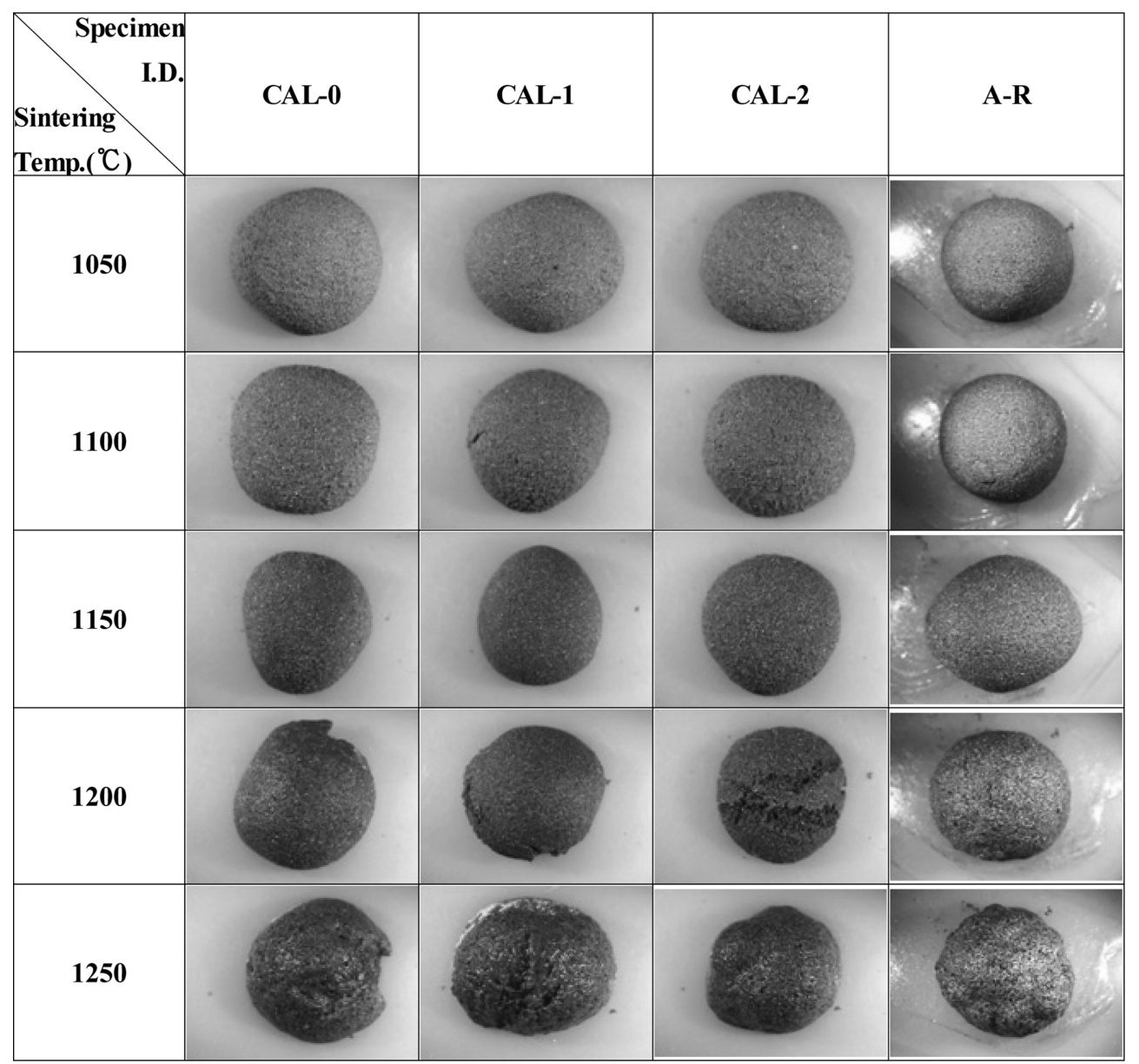

Fig. 4. Optical microscopic photographs for external appearance of artificial aggregates sintered at $1050 \sim 1250^{\circ} \mathrm{C}$ for $10 \mathrm{~min}$ in electric furnace.

며, 중심부의 검은색은 환원된 $\mathrm{FeO}$ 때문으로 알려져 있 다[8]. 탄소의 산화반응은 $\mathrm{Fe}_{2} \mathrm{O}_{3}$ 의 환원을 촉진하므로, 탄소함량이 많은 시편일수록 내부의 블랙코어 크기가 넓 게 나타난 것으로 생각된다. 따라서 탄소함량이 가장 많은 $\mathrm{AR}$ 의 시편은 탄소량이 적은 다른 시편과 달리 $1050^{\circ} \mathrm{C}$ 의 낮은 소결온도에서도 블랙코어 현상을 나타내었다.

잔사회를 하소시킨 뒤 골재 원료로 사용하여 제조된 시편 중 $\mathrm{CAL} 1$ 및 $\mathrm{CAL} 2$ 시편은 $1100^{\circ} \mathrm{C}$ 에서 $1150^{\circ} \mathrm{C}$ 로 소결온도가 증가해도 $\mathrm{CAL} 0$ 와 같은 급격한 밀도증가 현 상이 나타나지 않았는데(Fig. 1 참조), 이러한 결과는 Fig. 3 의 단면 관찰 결과와 잘 일치한다. $1050 \sim 1150^{\circ} \mathrm{C}$ 의 구간에서, CAL1 및 CAL2 시편은 온도에 따라 밀도 가 증가하는 치밀화 과정이 나타났으나 동시에 약간의 블랙코어 현상도 함께 발생하였기 때문에 온도에 따른 밀도증가 기울기가 CALO에 비해 낮은 것을 알 수 있다. $1150^{\circ} \mathrm{C}$ 이상에서는 모든 시편의 밀도가 급히 감소하였 으며(Fig. 1 참조), 이는 Fig. 3의 단면구조에서 확인할 수 있듯이 블랙코어 현상에 의한 발포 때문이다.

하소하지 않은 잔사회를 사용한 $\mathrm{AR}$ 시편의 단면을 보
면, $1150^{\circ} \mathrm{C}$ 이상의 고온 소결에서도 블랙코어가 발생하 지 않았고, 표면에 작은 기공들이 몰려있는 표면발포 현 상을 나타내었다. 이는 A R시편의 밀도가 소성온도 증 가에도 큰 변화를 보이지 않는 Fig. 1 의 결과와도 잘 일 치한다. 또한 $1150^{\circ} \mathrm{C}$ 이상의 소결온도에서 내부에 방사 형 균열이 발생되었는데, 이는 과량의 탄소가 일시에 가 스를 형성하여 외부로 빠져나가는 과정에서 일어난 것으 로 생각된다. 이러한 방사형 균열은 시편의 밀도를 약간 감소시키는 원인이 된다(Fig. 1 참조).

탄소함량에 따른 골재 표면 관찰 사진을 Fig. 4에 나 타내었다. 소성온도 $1200^{\circ} \mathrm{C}$ 에서 시편 표면에 균열 현상 이 나타났다. 이는 골재 내에 발포로 인하여 골재의 부 피가 커지면서 표면이 갈라졌기 때문으로 생각된다. 그 런데 $1250^{\circ} \mathrm{C}$ 에서는 표면 균열 흔적만이 남아있음을 볼 수 있다. 이는 액상이 다량으로 형성되어 표면 균열을 매워주었기 때문으로 판단된다. 실제 육안으로도 CAL0 시편 포면에는 다른 시편들에 비해 더 많은 액상이 형성 되어 있음을 확인할 수 있었다. 이로 인해 CAL0 시편 의 흡수율이 소결온도에 따라 급속히 감소된 것이다 
(Fig. 2). 골재 내 탄소 함량이 높아지면, 표면 발포 현상 으로 인하여 표면에 많은 개기공이 형성된 것이 관찰되 었다. 특히 탄소함량이 제일 높은 $\mathrm{AR}$ 시편에서 그 현상 이 두드러지게 나타났다. 이러한 관찰 결과를 Fig. 2의 흡수율 데이터와 연관시키면 개기공 형성이 골재 흡수율 을 높이는 원인임을 알 수 있다.

본 연구에서는 바닥재, 준설토 그리고 잔사회를 원료 로 사용하여 원료의 하소 유무, 활성 탄소 첨가량 그리 고 소결온도 제어를 통해 부피비중이 $0.95 ~ 1.55$, 흡수율 이 $5 \sim 29 \%$ 범위인 다양한 특성의 인공경량골재를 제조 할 수 있었다. 따라서 본 연구에서 제조된 인공경량골재 는 수질 정화용 담체, 토목 및 건축용 경량자재, 도시농 공업용 토양 등 다양한 분야에 적용이 가능할 것으로 판 단되며 이에 따라 기존에 재활용이 어려웠던 석탄 잔사 회 및 바닥재의 재활용율이 높아질 것으로 기대된다.

\section{4. 결 론}

화력발전소에서 발생된 바닥재, 준설토 그리고 잔사회 를 원료로 하여 골재를 제조함에 있어 잔사회를 하소하 고, 활성탄소를 첨가하여 골재 내 탄소함량을 실험인자 로 하여 다음과 같은 결과를 얻었다.

하소한 잔사회를 사용한 골재의 경우, 소성온도에 따 라 골재 비중값은 증가하다가 특정 온도 이후에는 다시 낮아지는 발포특성을 보였으나, 잔사회를 그대로 사용한 골재의 발포 경향은 미미하였다. $1250^{\circ} \mathrm{C}$ 에서 소성된 하 소 계열 시편들의 비중값은 모두 0.95 에 수렴하였다. 골 재 흡수율은 소성온도 증가에 따라 감소하는 경향을 보 였으며 활성탄소 함량에 따른 감소 기울기가 완만해졌다. 이는 탄소함량이 높은 골재일수록 표면발포 거동을 나타 내고, 따라서 표면에 개기공이 형성이 되어 흡수율이 높 아졌기 때문이다. 또한 골재 내 활성 탄소 함량이 증가 함에 따라 내부 블랙코어에 형성되었던 기공이 점차 표 면으로 옮겨지는 것을 미세구조에서 관찰하였다. 특히 블랙코어의 면적은 내부 탄소의 양이 많아짐으로 인하여 더욱 넓어졌다.
본 연구에서는 제조된 인공골재는 부피비중이 0.95 1.55 , 흡수율이 5 29\%로 다양한 물성을 나타내었고, 따 라서 수질 정화용 담체, 토목 및 건축용 경량자재, 도시 농공업용 토양 등의 분야에 적용할 수 있을 것으로 판단 된다. 아울러 기존에 재활용이 어려웠던 석탄 잔사회 및 바닥재의 재활용율이 높아질 것으로 기대된다.

\section{감사의 글}

본 연구는 2011학년도 경기대학교 학술연구비(일반연 구과제) 지원에 의하여 수행되었음.

\section{참 고 문 헌}

[1] Korea Electric Power Industrial Development Corporation, http://www.kepid.co.kr.

[2] K.J. Kwon, "Utilization of fly ash \& bottom ash as concrete materials", J. Arch. Ins. Kor. 54[2] (2010) 46.

[ 3 ] A. Barba, F. Negre, M.J. Orts and A. Escardino, "Oxidation of black coring during the firing of ceramic ware-3. Influence of the thickness of the piece and the composition of the black core", Br. Ceram. Trans. and Jour. 91 (1992) 36.

[4] K.D. Kim, "A Study on application and fabrication of functional ceramics for constructing materials using ecofriendly waste recycling process", Doctoral dissertation, Kyonggi University (2010).

[5] W.E. Brownell, "Black coring in structural clay products", J. Am. Ceram. Soc. 40(6) (1957) 179.

[ 6 ] K.J.D. MacKENZIEA and C. M. Cardile, " ${ }^{57} \mathrm{Fe}$ Mössbauer study of black coring phenomena in clay-based ceramic materials", J. Mater. Sci. 25 (1990) 2937.

[ 7 ] M.A. Kang and S.G. Kang, "Characterization of artificial aggregates fabricated from coal bottom ash containing much unburned carbon", J. Kor. Cryst. Growth and Cryst. Tech. 21[1] (2011) 47.

[ 8 ] K.D. Kim and S.G. Kang, "Characterization of artificial aggregates fabricated with direct sintering method", J. Kor. Cryst. Growth and Cryst. Tech. 21[1] (2011) 34. 